\title{
How to Present more Readable Text for People with Dyslexia
}

\author{
Luz Rello • Ricardo Baeza-Yates
}

Received: date / Accepted: date

\begin{abstract}
The presentation of a text has a significant effect on the reading speed of people with dyslexia. This paper presents a set of recommendations to customize texts on a computer screen in a more accessible way for this target group. This set is based in an eye tracking study with 92 people, 46 with dyslexia and 46 as control group, where the reading performance of the participants was measured. The following parameters were studied: color combinations for the font and the screen background, font size, column width as well as character, line and paragraph spacing. It was found that larger text and larger character spacing lead the participants with and without dyslexia to read significantly faster. The study is complemented with questionnaires to obtain the participants preferences for each of these parameters, finding other significant effects. These results provide evidence that people with dyslexia may benefit from specific text presentation parameters that make text on a screen more readable. So far, these recommendations based on eye tracking data are the most complete for people with dyslexia.
\end{abstract}

Keywords Dyslexia - eye tracking · textual accessibility · text customization - recommendations .

Luz Rello

Human-Computer Interaction Institute

Carnegie Mellon University, USA

E-mail: luzrello@acm.org

(this research was conducted while the first author was doing her PhD at the Web Research Group, Universitat Pompeu Fabra, Barcelona)

Ricardo Baeza-Yates

Yahoo Labs, Sunnyvale, CA, USA \&

Web Research Group

Universitat Pompeu Fabra, Barcelona

E-mail: rbaeza@acm.org readability - text color $\cdot$ background color $\cdot$ font size . character, line and paragraph spacings $\cdot$ column width.

\section{Introduction}

Dyslexia is a neurological reading disability which is characterized by difficulties with accurate and/or fluent word recognition and by poor spelling and decoding abilities. Secondary consequences may include problems in reading comprehension and reduced reading experience that can impede growth of vocabulary and background knowledge [43]. Since a great amount of information is presented as text, this condition makes more difficult for people with dyslexia to access written information. At the same time, access to information and communication technologies is recognized as a basic human right by United Nations [102].

Related to its social relevance, there are two reasons motivating the decision to approach textual accessibility for users with dyslexia: first, they are a relatively large group of users, since dyslexia is frequent and universal, and second, this kind of accessibility practices are not only good for people with dyslexia but also for other target groups.

Frequent and universal. There is a universal neurocognitive basis for dyslexia [65] but its manifestations are variable due to different orthographies [35]. Depending on the language, the estimations of dyslexia varies. The Interagency Commission on Learning Disabilities [42] states that $10-17.5 \%$ of the population in the U.S.A. has some level of dyslexia while Brunswick [16] estimates $10 \%$ for English and $3.5 \%$ for Italian. According to different statistics, from 8.6 [45] to $11 \%$ [18] of the Spanish speaking population has dyslexia. The authors 
made an estimation of the presence of dyslexic texts in the Web and the results show that at least $0.67 \%$ of the spelling errors found in the English Web [3] and 0.43 in the Spanish Web [78] are made by people with dyslexia.

Good for others groups. The use of Web accessibility practices for people with dyslexia is beneficial for all, since dyslexic-accessible practices alleviate difficulties faced by all Internet users, as well as other users with disabilities $[26,31,55,69,111]$. According to Zarach [111], the guidelines to enhance readability for people with dyslexia, also benefit people without dyslexia. For example, Dixon [26] tested a piece of educational software with dyslexic and non-dyslexic readers and the results suggest that the symptoms of dyslexia are common to varying degrees among most people. Pollak [69] showed how students with and without dyslexia benefit from using multimodal documents. Also, Evett and Brown [31] found that the web style guidelines for blind or low vision readers are closely parallel to those for dyslexic readers. Later, McCarthy and Swierenga remark the overlap of dyslexic-accessible recommendations with more general textual accessibility recommendations [55]. Hence, the present work is also extensible to general usability problems and to other target groups.

Previous research indicate that the text presentation may have an impact on the reading performance of people with dyslexia $[1,37,50]$. To the best of the authors' knowledge, this is the first time that eye tracking is applied with such an extensive group of people, 46 participants with dyslexia and 46 without dyslexia, to define dyslexic-accessible text presentation recommendations. The present proposal would improve the ability of people with dyslexia to read and access a wider range of information content, empowering them by slightly leveling the playing field. This paper presents the following main contributions:

- Larger font size, ranging from 18 to 26 points, lead people with and without dyslexia to read significantly faster.

- Larger character spacing, ranging from $+7 \%$ to $+14 \%$, lead people with and without dyslexia to read significantly faster compared to smaller character spacing $(-7 \%)$.

- Black text on white background instead of using grey scales for the text is significantly preferred by people with and without dyslexia.

- White text on black background instead of using grey scales for the background is significantly preferred by people with and without dyslexia.

The rest of the paper is organized as follows. In Section 2 dyslexia is defined and the common problems that people with dyslexia encounter are explained. Section 3 covers related work. Section 4 explains the experimental methodology, while Section 5 presents the results. Section 6 presents a discussion and Section 7 the limitations of the study. Finally in Section 8 a set of recommendations is proposed. Conclusions and future challenges are given in Section 9.

\section{Dyslexia}

Brain structure, brain function and genetics studies confirm the biological foundations of dyslexia [104]. However, despite its universal neuro-cognitive basis, dyslexia manifestations are variable and culture-specific [35]. This variability is due to the different language orthographies concerning their grade of consistency and regularity [16]. English has an opaque -or deep- orthography in which the relationships between letters and sounds are inconsistent and many exceptions are permitted. English presents a significantly greater challenge to young readers than other languages, such as Spanish or Italian, with a more regular alphabetic system that contains consistent mappings between letters and sounds, that is, a transparent -or shallow- orthography. For instance, in [65], Italian participants with dyslexia performed better on reading tasks than English people with the same condition. Along an orthographic transparency scale for European languages, English appears as the language with the deepest orthography and Spanish as the second most shallow after Finnish [93]. Since the challenge of mapping phoneme to grapheme depends on the orthographic transparency of the language, Spanish shall be not be as challenging as other languages according to this scale [93].

Hence, for the reasons described above, dyslexia has been called a hidden disability, due to the difficulty of its diagnosis in languages with shallow orthographies [104], where diagnoses depend more on reading speed that on the errors [24].

People with dyslexia encounter problems, not only with some text presentation conditions, such as small font size $[55,89]$, but also with language-related conditions. The following presents the dyslexia-related difficulties according to their language level. They were collected from the cognitive neuroscience literature, with the exception of the discourse level, where there are recommendations from Web accessibility literature. The poorer reading comprehension which characterized dyslexia in this level has also been included because text comprehension depends on longer segments of texts, not only words. These difficulties are: 
(a) Orthography:

- Orthographically similar words, e.g. addition and audition $[28,95]$;

- alternation of different typographical cases, e.g. ElefANte ('elefante') [56];

- letter recognition [7,10];

- number recognition $[20,51,84]$; and

- poor spelling, such as letter reversals, e.g. trail for trial $[2,15,43,109]$.

(b) Phonology:

- Irregular words, e.g. vase ${ }^{1}[22,28,95]$; and

- homophonic words or pseudo homophonic words, like weather and whether [33,62].

(c) Morphology:

- Derivational errors, e.g. discomfortable [64,95, 103].

(d) Lexicon:

- New words, e.g. fantabulous [6,24];

- pseudo-words and non-words, ${ }^{2}$ e.g. happisfaction $[27,70,95,103]$;

- less frequent words, e.g. pristine [34,82,88,92];

- long words, e.g. prestidigitation $[24,63,82,107]$;

- word additions, omissions and word recognition $[13,14,43,54]$;

- substitutions of functional words, ${ }^{3}$ e.g. of by for $[64,95,107]$

- confusions of small words, e.g. in buy is, or buy and but $[24,105]$; and

- misspellings recognition [39,77].

(e) Discourse:

- Short sentences and short paragraphs benefit accessibility for people with dyslexia according to Web accessibility literature $[9,11,61]$.

- Poor reading comprehension [104]. In dyslexia this is related to decoding and not to problems in oral or listening comprehension [23], that is, in dyslexia, normally poor comprehension is caused by a decoding mistake, such as word recognition. Oral and reading comprehension need to be differentiated, since decoding and listening comprehension have been shown to have different implications in measuring comprehension [48]. Dyslexia affects decoding, though not listening comprehension $[38,57]$.

Additionally, there are visual difficulties associated with dyslexia [29] that could be alleviated by modifi-

\footnotetext{
1 Words with no consistent correspondence between grapheme and phoneme, e.g. vase pronounced as /vāz/.

2 A non-word is a word that has no meaning, is not known to exist, or is disapproved.

3 Functional words are words that have little lexical meaning, but instead serve to express grammatical relationships with other words within a sentence.
}

cations of the visual display. The most studied in relationship with dyslexia is the visual stress syndrome (Meares-Irlen syndrome) [49]. The Meares-Irlen syndrome is characterized by symptoms of visual stress and visual perceptual distortions that are alleviated by using individually prescribed colored filters. Also patients susceptible to pattern glare, that is perceptual distortions and discomfort from patterns, are prone to Meares-Irlen syndrome and are also likely to find colored filters useful [30]. Kriss and Evans [49] compared colored overlays on a group of 32 children with dyslexia with a control group of same size. The difference in prevalence of the two groups did not reach statistical significance. The authors conclude that Meares-Irlen syndrome is prevalent in the general population and possibly a little more common in dyslexia. Children with dyslexia seemed to benefit more from colored overlays than non-dyslexic children. The authors stress that Meares-Irlen syndrome and dyslexia are separate entities and are detected and treated in different ways [49]. Moreover, Jeanes et al. [44] showed how color overlays helped the reading of children in school whithout taking into consideration dyslexia or other visual difficulties. Gregor and Newell [37] and later Dickinson et al. [25] have shown that visual changes in the presentation of text may alleviate some of the problems generated by dyslexia and the visual comorbidities related to dyslexia.

\section{Related Work}

According to a survey by McCarthy and Swierenga [55], studies about dyslexia and accessibility are scarce compared to other groups of users with special needs. However, Al-Wabil et al. [1] claim that there are considerable barriers for people with dyslexia.

In the Web Content Accessibility Guidelines (WCAG) [17], dyslexia is only one more disability within a diverse group of cognitive disabilities. According to Santana et al. [89] this lack of explicit consideration of dyslexia specificities in the guidelines make the needs of users with dyslexia unfulfilled.

Previous work has been divided in user studies about text customization and recommendations.

\subsection{User Studies}

Gregor and Newell [37] asked 12 students with dyslexia to test different colors, sizes, spacings, column widths, and similar letter highlighting to improve the subjective readability of MS Word documents. The best parameters were tested by seven people with dyslexia, which 
reported a subjective increase in readability. The results of this investigation were included in the SeeWord tool for MS Word [36]. After, Dickinson et al. [25] carried out a pilot study with six participants using the SeeWord software showing that reading accuracy improved as well as the subjectively rated reading comfort.

Kurniawan and Conroy [50] tested different color schemes for reading online with 27 users with dyslexia. The participants had to read five online articles and undertook comprehension questionnaires. The comprehension of readers with dyslexia was poorer for the complex articles however the reading speed was not slower using the color scheme the users selected.

Santana et al. [90] developed the Mozilla Firefox extension Firefixia, a tool that allows readers with dyslexia to customize websites to improve readability. They tested Firefixia with four users and found that readers with dyslexia appreciate customization. The customization settings included in Firefixia are based in previous user studies and recommendations. They include font type, font size, color, character spacing, line spacing and column width.

O'Brien et al. [59] compared the reading speeds using twelve different font sizes between two groups: children with (aged 7 to 10 years), and without dyslexia (aged 6 to 8 years). They showed how dyslexic reading follows the same curve shape as skilled reading, with constant reading rates across large font sizes and a sharp decline in reading rates below a critical font size. Readers with dyslexia presented higher critical font sizes.

Zorzi et al. [113] conducted an experiment with 74 children with dyslexia (34 Italian and 40 French, aged between 8 and 14). The children read on paper texts with regular character spacing and extra large character spacing (an increase of 2.5 pt in the standard letter spacing using 14 points Times font). The texts with larger character spacing lead to a better reading accuracy (number of errors) and speed (number of syllables per second).

Schneps et al. [91] performed an experiment with 27 high school students with reading struggles. They tested line length and extra large spacing. Regarding line length, they compare two screen dimensions: iPod Touch in portrait mode $(5 \mathrm{~cm} \times 7.5 \mathrm{~cm})$ and the Apple iPad in landscape mode $(19.7 \mathrm{~cm} \times 14.8 \mathrm{~cm})$. They found that using a small device improved readability (faster reading speeds, less number of fixations and less regressive saccades). With regards to extra large spacing they conclude that it improves comprehension in those most impaired.

In the authors' previous work, Rello et al. [86] tested the same parameters of the present study. Eye tracking, questionnaires and semi-structured interviews with 23 participants with dyslexia were used, testing grey scales and colors for the text and the background, character, line and paragraph spacing as well as column width. The results were integrated in two text customization tools: the web service Text4All $[99]^{4}$ for websites and the Android IDEAL eBook reader ${ }^{5}$ [47] for ebooks. Its functionalities and usability were tested with 14 participants with dyslexia using the think aloud protocol [52]. The participants reported a subjective improvement of the reading comfort and functional improvements proposed by the participants (mainly to the interface) were subsequently integrated in the application.

\subsection{Recommendations}

There is a common agreement in specific studies about dyslexia and accessibility that the application of dyslexic-accessible practices benefits also the readability for users without dyslexia [26,50,55]. Consequently, the guidelines for developing Web sites accessible to users with dyslexia [11,71,111] usually overlap with guidelines for low-literacy users [58] or other disabilities such as low vision [31]. For example, according to Zarach [111] guidelines for enhanced readability for people with dyslexia, also benefit people without dyslexia. However, there is no universal profile of a user with dyslexia and therefore some authors recommend using a customizable environment for such users [37,58].

In relationship with the variables studied in the experiments, the recommendations for text presentation for people with dyslexia have focused in the following parameters: text and background grey scale [86,101], text and background colors $[11,12,37,71,86]$, font size $[1,12,25,71,86,111]$, paragraph spacing $[11,86]$, character spacing [66,71], line spacing $[71,86]$ and column width $[11,12,86]$.

Except from preliminary work [86], this study differs from the rest of the related approaches specifically in the application of eye tracking to measure readability of a text. The current study addresses the methodological weaknesses of the authors' previous work improving it in the following points:

- The results are based in a larger number of participants with dyslexia (46 participants instead of 23).

- The results are compared with a similar control group without dyslexia (46 people).

- Text comprehension is included as a control variable.

\footnotetext{
4 http://www.text4all.net/dyswebxia.html

5 https://play.google.com/store/apps/details?id= org. easyaccess.epubreader
} 
- The presentation of the conditions are counterbalanced, instead of randomized, to cancel out order effects. Each of the counter-balanced conditions was read by the same number of participants.

\section{Methodology}

Eight experiments were conducted to study the effect of eight text presentation parameters on readability. In the experiments, 92 participants (46 with dyslexia) had to read a set of texts, which were altered to include the different values of the parameters.

\subsection{Design}

For each experiment there were four or eight conditions. Each of the conditions correspond with the levels of the parameters taken as independent variables. The experiments followed a within-subjects design, so every participant contributed to each of the conditions in the experiments. The order of the experimental conditions was counter-balanced to cancel out sequence effects. No combinations of conditions were studied. Table 1 shows a summary of the experiments.

The levels of the variables were chosen taking into account the difficulties that people with dyslexia find (see Section 2); previous user studies (see Section 3); and literature about recommendations for readers with dyslexia (see Section 3). More details of the parameters used in comparison with the literature are given in Section 6 . The following presents the independent variables and their levels.

Grey Text (white background): This independent variable has four levels corresponding to four grey scale values for the text with white background: $0 \%$ (black font), $25 \%, 50 \%$ and $75 \%$ (See Figure 1, left). ${ }^{6}$

Grey Background (white text): This independent variable has four levels corresponding with to grey scale values for the background with white text: $0 \%$ (black background), 25\%, $50 \%$ and $75 \%$ (See Figure 1, left). ${ }^{6}$

Text and Background Color: Eight color pairs (text/background) were tried: black/white, offblack/off-white, black/yellow, blue/white, black/creme, dark brown/light mucky green, brown/mucky green and blue/yellow (See Figure 1, middle). ${ }^{6}$

6 The CYMK code for the colors and their contrast are shown in Appendix A.
Font size: This independent variable has four levels corresponding to four font sizes: 14, 18, 22 and 26 points (See Figure 1, right).

Character spacing: This independent variable has four levels corresponding to four distances between characters: $-7 \%, 0 \%,+7 \%$ and $14 \%$ (See Figure 1, right). ${ }^{7}$

Line spacing: This independent variable has four levels corresponding to four values for spacing: 0.8, 1, 1.2 and 1.4 lines. Each of the texts tested were composed of seven lines.

Paragraph spacing: This independent variable has four levels corresponding to four values for the spacing between paragraphs: $0.5,1,2$ and 3 lines. To test paragraph spacing each of the slides contained three paragraphs.

Column width: This independent variable has four levels corresponding with four values for column width tested: 22, 44, 66 and 88 characters per line (as the fonts have letters with variable width, this is the average number of characters per line).

To measure objective readability, eye Fixations $D u$ ration is considered as dependent variable. To control text comprehension of the texts a Comprehension Score as a control variable is used and to collect the participant subjective preferences the Preference Ratings of the participants were used. They are explained in detail in the following.

Fixation Duration (objective readability): When reading a text, the eye does not move contiguously over text, but alternates saccades and visual fixations, that is, jumps in short steps and rests on parts of the text. Fixation duration denotes how long the eye rests still on a single place of the text. The means of the fixation duration are used as a performance metric. This data is obtained directly from the eye tracker software.

Fixation duration has been shown to be a valid indicator of readability. Rayner [74] presents a review of the studies using eye movements to investigate cognitive processes that have appeared since the mid-1970s to the 1990s and argues that eye movement measures can be used to infer moment-to-moment cognitive processes in reading. Shorter fixations are associated with better readability, while longer fixations can indicate that processing loads are greater. For instance, readers

7 Although there are others units that can be used, the simplest is to use a percentage of the current font size. 


\begin{tabular}{|c|c|c|}
\hline Design & \multicolumn{2}{|l|}{ Within-subjects } \\
\hline \multirow[t]{8}{*}{$\begin{array}{l}\text { Independent } \\
\text { Variables } \\
\text { (one per experiment) }\end{array}$} & $\begin{array}{l}\text { Color } \\
\text { (text and background) }\end{array}$ & $\begin{array}{l}\text { black/white } \\
\text { off-black/off-white } \\
\text { black/yellow } \\
\text { blue/white } \\
\text { black/creme } \\
\text { blue/yellow } \\
\text { dark brown/light mucky green } \\
\text { brown/mucky green }\end{array}$ \\
\hline & Grey Text (white background) & $\begin{array}{l}0 \% \text { (black font) } \\
25 \% \\
50 \% \\
75 \%\end{array}$ \\
\hline & Grey Background (white text) & $\begin{array}{l}0 \% \text { (black background) } \\
25 \% \\
50 \% \\
75 \%\end{array}$ \\
\hline & Font Size & $\begin{array}{l}14 \text { points } \\
18 \text { points } \\
22 \text { points } \\
26 \text { points }\end{array}$ \\
\hline & Character Spacing & $\begin{array}{l}-7 \% \text { character } \\
0 \% \text { character } \\
+7 \% \text { character } \\
14 \% \text { character }\end{array}$ \\
\hline & Line Spacing & $\begin{array}{l}0.8 \text { lines } \\
1 \text { line } \\
1.2 \text { lines } \\
1.4 \text { lines }\end{array}$ \\
\hline & Paragraph Spacing & $\begin{array}{l}0.5 \text { lines } \\
1 \text { line } \\
2 \text { lines } \\
3 \text { lines }\end{array}$ \\
\hline & Column Width & $\begin{array}{l}22 \text { character per line } \\
44 \text { character per line } \\
66 \text { character per line } \\
88 \text { character per line }\end{array}$ \\
\hline $\begin{array}{l}\text { Dependent } \\
\text { Variables } \\
\text { Control Variable }\end{array}$ & $\begin{array}{l}\text { Fixation Duration } \\
\text { Preference Rating } \\
\text { Comprehension Score }\end{array}$ & $\begin{array}{l}\text { (objective readability) } \\
\text { (subjective preferences) } \\
\text { (objective comprehensibility) }\end{array}$ \\
\hline \multirow[t]{2}{*}{ Participants } & $\overline{\text { Group D (46 participants) }}$ & $\begin{array}{l}26 \text { female, } 20 \text { male } \\
\text { Age: range from } 11 \text { to } 45 \\
(\bar{x}=20.70, s=7.87) \\
\text { Education: high school }(22), \\
\text { university }(21), \text { no higher education }(3)\end{array}$ \\
\hline & Group C (46 participants) & $\begin{array}{l}27 \text { female, } 19 \text { male } \\
\text { Age: range from } 13 \text { to } 37 \\
(\bar{x}=23.50, s=8.16) \\
\text { Education: high school }(16), \\
\text { university }(28), \text { no higher education }(2)\end{array}$ \\
\hline Materials & $\begin{array}{l}\text { Base Texts } \\
\text { Text Presentation } \\
\text { Comprehension Questionnaire } \\
\text { Preferences Questionnaire }\end{array}$ & $\begin{array}{l}36 \text { text fragments } \\
8 \text { inferential items }(1 \text { item/condition }) \\
8 \text { items }(1 \text { item/condition })\end{array}$ \\
\hline Equipment & \multicolumn{2}{|l|}{ Eye tracker Tobii 1750} \\
\hline$\overline{\overline{\text { Procedure }}}$ & \multicolumn{2}{|c|}{$\begin{array}{l}\text { Steps: Instructions, demographic questionnaire, reading task, } \\
\text { comprehension questionnaire, preference questionnaires }\end{array}$} \\
\hline
\end{tabular}

Table 1 Experimental methodology summary for the experiments. 
Fig. 1 Examples of the text and background grey scales and colors used, as well as character spacing and font size.

\begin{tabular}{|c|c|c|c|c|c|c|c|c|c|c|}
\hline dyslexia & dyslexia & $\begin{array}{l}\text { grey scale: } \\
0 \%\end{array}$ & dyslexia & $\begin{array}{l}\text { black/ } \\
\text { white }\end{array}$ & dyslexia & $\begin{array}{l}\text { black/ } \\
\text { creme }\end{array}$ & dyslexia & $\begin{array}{l}\text { char. spacing: } \\
+14 \%\end{array}$ & dyslexia & $\begin{array}{l}\text { Size: } \\
14 \text { points }\end{array}$ \\
\hline dyslexia & dyslexia & $25 \%$ & dyslexia & $\begin{array}{l}\text { off-black/ } \\
\text { off-white }\end{array}$ & dyslexia & $\begin{array}{l}\text { dark brown/ } \\
\text { light mucky green }\end{array}$ & dyslexia & $+7 \%$ & dyslexia & 18 points \\
\hline dyslexia & dyslexia & $50 \%$ & dyslexia & $\begin{array}{l}\text { black/ } \\
\text { yellow }\end{array}$ & dyslexia & $\begin{array}{l}\text { brown/ } \\
\text { mucky green }\end{array}$ & dyslexia & $0 \%$ & dyslexia & 22 points \\
\hline dyslexia & dyslexia & $75 \%$ & dyslexia & $\begin{array}{l}\text { blue/ } \\
\text { white }\end{array}$ & dyslexia & $\begin{array}{l}\text { blue/ } \\
\text { yellow }\end{array}$ & dyslexia & $-7 \%$ & dyslexia & 26 points \\
\hline
\end{tabular}

present longer fixations at low-frequency words than at high-frequency words $[41,46,72,75,76]$.

There are three studies that show why fixation duration is also a valid indicator for people with dyslexia. First, Hyöna and Olson [40] found that dyslexic readers show the typical word frequency effect in which lowfrequency words are fixated longer than high-frequency words.

Second, Pirozzolo and Rayner [68] and Olson et al. [60] found that when dyslexic readers were given a text appropriate for their reading level, their eye movements (fixations, saccades and regressions) were much like those of normal readers at that particular age level.

Third, Rayner [73] showed that normal children's eye movements (fixation durations, saccade lengths, and the size of the perceptual span) could be similar to the dyslexic readers' eye movements when they were given a text that was too difficult for them.

In sum, as Rayner [74] concludes "the most appropriate conclusion remains that eye movements reflect the difficulties that dyslexic individuals have reading and are not the cause of the reading problem".

Comprehension Score (objective comprehensibility): Moving the eyes over a text does not guarantee its comprehension, specially in people with dyslexia where comprehension was found to be independent from readability [77]. To check that the text was not only read, but also understood, text comprehension is measured using a comprehension questionnaire with inferential items, that is, questions that require a deep understanding of the content of the text. They include multiplechoice questions with three possible choices, one correct choice and two wrong choices. Each item referred to the understanding of the whole stories presented because fragments presented were too short to ask comprehension questions for each fragment. From these answers, a comprehension score, the percentage of correct answers is computed, where the correct choice scored $100 \%$ and the others $0 \%$. To guarantee that recordings analyzed in this study were valid and comparable, the comprehension score was used as a control variable, such that if the recording of a complete session did not have an overall $100 \%$ comprehension score, it was discarded from the analysis.

Preference Rating (subjective preferences): To measure the participants' preferences, they were asked to select the texts that they found easiest to read. For each experiment, they wrote their answers in a paper questionnaire while they saw the options on the screen. The participant could see the options for as long and as many times as desired. Whenever the participant selected one, two, three or four options as most readable, the weights $1,0.5,0.33$ and 0.25 respectively, were given to those options. To calculate the average preference rating the weights are summed and then divided by the number of participants.

\subsection{Participants}

Overall, 92 participants undertook the experiment. They included 46 Spanish speakers (26 female, 20 male) with a confirmed diagnosis of dyslexia (group D) and 46 Spanish speakers (27 female, 19 male) without dyslexia, which served as a control group (group C). The ages of group D ranged from 13 to 37 , with a mean age of 23.50 years $(s=8.16)$, while the ages of group $\mathrm{C}$ ranged from 13 to 43 , with a mean age of 20.70 years $(s=7.87)$.

Apart from 3 participants with dyslexia and 2 without dyslexia who had no higher education, the rest were attending school or high school (22 participants with dyslexia and 16 participants without dyslexia) or were studying or had already finished university degrees (21 participants with dyslexia and 28 participants without dyslexia).

Participants from group D were asked to bring their diagnoses to the experiment, to guarantee that dyslexia was diagnosed in an authorized centre or hospital. In the Catalan protocol of dyslexia diagnosis [94], the different kinds of dyslexia, extensively found in literature, are not considered. Therefore, one can only guarantee that the participant was diagnosed in a authorized center or hospital but not the exact type of dyslexia. Three 
of these participants were also diagnosed with attention deficit disorder. None of the participants were screened for visual stress (Meares-Irlen) syndrome.

\subsection{Materials}

The materials used in the experiment were: base texts, comprehension questionnaires, and preferences questionnaires. The test presentation was also controlled.

\subsubsection{Base Texts}

For the reading tests two stories were used. The first story $^{8}$ was written in verse, while the second is a fragment in prose. ${ }^{9}$

The overall text was divided in 36 fragments and each of them was presented to the participants with a different condition. To maintain the independence of the variables, there were no combinations among the conditions levels. The texts fragments belonging to different levels of the same condition were comparable to each other. They had the same number of words and the same number of syllables for the shorter passages (texts containing less than 22 words). The shorter texts were extracted from the story written in verse so they were very similar to each other having the same rhythm and meter.

\subsubsection{Comprehension Questionnaire}

Multiple-choice questions with three possible choices, one correct choice and two wrong were used. The comprehension questionnaire was composed of three items about the general content of the text. An example of an item is given below.

\footnotetext{
- ¿Por qué querían matar las hormigas a su compañera? 'Why did the ants wanted to kill their comrade?'

- Porque era egoísta. 'Because she was selfish'.

- Porque veía las estrellas. 'Because she saw the stars'.

- Porque no rezaba. 'Because she did not pray'.
}

\subsubsection{Preferences Questionnaire}

The slides that the participant read were replayed and through a paper questionnaire, the participant chose what $\mathrm{s} /$ he thought was the best reading alternative between the options given for each of the parameters. The questionnaire had eight items, one for each experiment,

8 Los Encuentros del Caracol Aventurero (The Encounters of the Adventurous Snail) by Federico García Lorca.

9 From the book Soy dix-leso? (I am dys-dumb?) of the Papelucho series by Marcela Paz. This text example is given in Appendix B. and four to eight possible choices depending on the number of levels of the variable. Each item was composed of one statement and the options. The statement was always the same. See an example of an item below.

$\begin{array}{ccc}\text { - Leo mejor el texto... 'I read best the text...' } \\ 1 \square & 2 \square & 3 \square\end{array}$

\subsubsection{Text Presentation}

For the experiment it was decided to present the texts in Arial because of the following reasons. First, Arial is the most common font used on screen for the Web [19]. Second, Arial has been highly recommended in previous work. For instance, Evett and Brown [31] put in comparison recommendations for readers with low vision and dyslexia, and both groups agree in using Arial and Comic Sans. In addition, the British Dyslexia Association also recommends using Arial. Third, in Lockley's [53] study, Arial was the preferred font. Also in a recent study using eye tracking with 48 participants with dyslexia [79], Arial was the font which lead to shorter reading times compared to other eleven fonts. ${ }^{10} \mathrm{Un}-$ justified text was used, since justified text alignment produces irregular spacing between words that make reading harder $[11,66,71]$.

The default parameters of text presentation were black text and white background for colors (no text and background grey scales were taken into consideration), 20 points for font size, $0 \%$ for character spacing, 1 for line spacing, 1 for paragraph spacing, and 66 characters for column width.

\subsection{Equipment and Software}

The eye tracker used was the Tobii T50 [98] that has a 17-inch TFT monitor with a resolution of $1024 \times 768$ pixels. The time measurements of the eye tracker have a precision of 0.02 seconds. The eye tracker was calibrated for each participant and the light focus was always in the same position. The distance between the participant and the eye tracker was constant (approximately $60 \mathrm{~cm}$. or 24 in.) and controlled by using a fixed chair.

The software used for analyzing the eye tracking data was Tobii Studio 3.0 and the R 2.14.1 statistical software for the statistical analysis.

10 The fonts tested were: Arial, Arial Italic, Computer Modern Unicode, Courier, Garamond, Helvetica, Myriad, OpenDyslexic, OpenDyslexic Italic, Times, Times Italic, and Verdana [79]. 
Fig. 2 Participants' reading performance (fixation duration mean) and preference ratings in \% for text grey scales (white background).
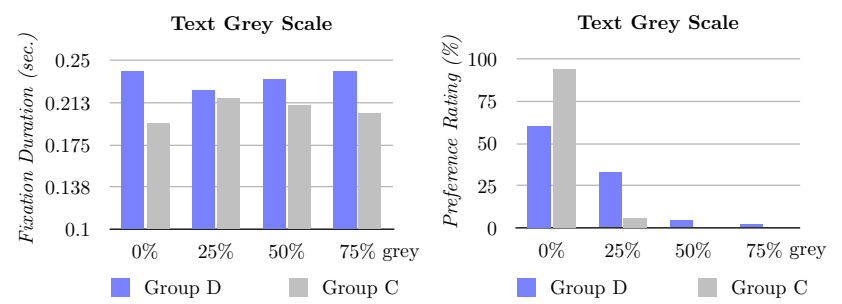

\subsection{Procedure}

The sessions were conducted at Pompeu Fabra University and needed thirty to forty minutes to complete. In each session the participant was alone with the interviewer (first author) in the quiet room prepared for the study, and had to carry out the steps presented in the following.

First, each participant was interviewed. The first interview began with a questionnaire designed to collect demographic information. Then, each participant watched a video with instructions. Third, the passages were recorded using eye tracking. The participant was asked to read in silence two stories contained in the test and answer the comprehension questionnaire. Finally, each participant filled in the user preferences questionnaire.

\section{Results}

This section presents the analyses of the data of both groups D and C. The comprehension score was used to filter the reading recordings. Recall that if the reading recording did not have an overall $100 \%$ comprehension score, we discarded it. Only one recording from the group D and two from group $\mathrm{C}$ were discarded.

A Shapiro-Wilk test showed that the datasets were normally distributed. Also, a Barlett's test showed that they were homogeneous. Hence, for each experiment the following were used:

- Two-way ANOVA test for repeated measures plus a complete pairwise post-hoc comparison using paired t-tests with a Bonferroni adjustment, to show effects of the conditions on fixation duration among groups $\mathrm{D}$ and $\mathrm{C}$.

- A one-way ANOVA test for repeated measures plus a complete pairwise post-hoc comparison using paired t-tests with a Bonferroni adjustment, to show the effects of the conditions on fixation duration within groups.
Fig. 3 Participants' reading performance (fixation duration mean) and preference ratings in \% for background grey scales (white text).
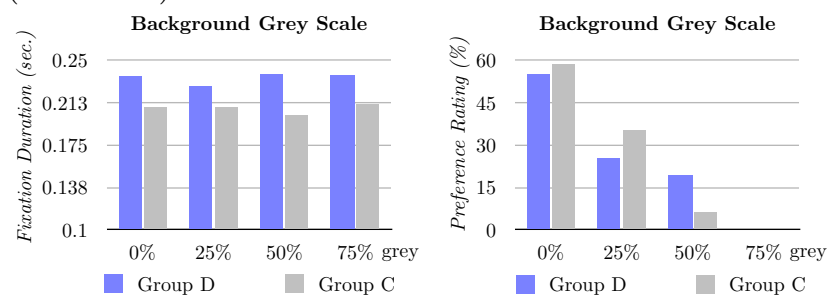

- Finally, a Pearson's Chi-squared test to show effects on the participants' choices.

Please refer to Table 2 for all the means and standard deviations.

\subsection{Grey Text (White Background)}

Main effects: With two-way ANOVA, significant main effects were found for the groups $(F(1,366)=$ $14.520, p<0.001)$ on fixation duration. However, no effects of text grey scale $(F(3,366)=0.086, p=0.968)$ on fixation duration were found. There were no interaction effects of text grey scale and the group $(F(3,366)=$ $1.400, p=0.242)$ either. The results of the post-hoc tests show that:

- Participants with dyslexia had significantly longer fixation times $(\bar{x}=0.234, s=0.08$ seconds) than the participants without dyslexia $(\bar{x}=0.206, s=$ 0.06 seconds, $p<0.001$ ) (Table 2 ).

Within Groups: There was no significant effect of text grey scale on fixation duration for group $\mathrm{D}(F(3,183)=$ $0.459, p=0.711)$ nor for group $\mathrm{C}(F(3,183)=$ $1.305, p=0.274)$.

Preferences: Participants with and without dyslexia found black text significantly more readable than text presented with different grey scales $\left(\chi^{2}(3)=\right.$ 15.128, $p=0.002$ for group D and $\chi^{2}(3)=39.869, p<$ 0.001 for group $\mathrm{C}$ ).

See Figure 2 for the fixation duration means and preferences.

\subsection{Grey Background (White Text)}

Main effects: With two-way ANOVA, significant main effects were found for the groups $(F(1,376)=$ 14.630, $p<0.001)$ on fixation duration. However there were no effects of background grey scale $(F(3,376)=$ 


\begin{tabular}{|c|c|c|c|c|c|c|}
\hline \multirow[t]{2}{*}{ Conditions } & \multicolumn{2}{|c|}{ Group D } & \multicolumn{2}{|c|}{ Group C } & \multirow{2}{*}{$\begin{array}{c}\text { Group D } \\
\% \\
\end{array}$} & \multirow{2}{*}{$\begin{array}{c}\text { Group C } \\
\%\end{array}$} \\
\hline & $\bar{x} \pm s$ & $\%$ & $\bar{x} \pm s$ & $\%$ & & \\
\hline Grey Text (white background) & \multicolumn{4}{|c|}{ Fixation Duration } & \multicolumn{2}{|c|}{ Preference Rating } \\
\hline $0 \%$ (black) & $0.24 \pm 0.07$ & 7.62 & $\mathbf{0 . 1 9} \pm 0.05$ & - & 60.00 & 93.88 \\
\hline $25 \%$ & $\mathbf{0 . 2 2} \pm 0.08$ & - & $0.22 \pm 0.07$ & 11.86 & 32.60 & 6.12 \\
\hline $50 \%$ & $0.23 \pm 0.09$ & 4.48 & $0.21 \pm 0.06$ & 8.76 & 4.35 & - \\
\hline $75 \%$ & $0.24 \pm 0.09$ & 7.62 & $0.20 \pm 0.06$ & 5.15 & 2.17 & - \\
\hline Grey Background (white text) & \multicolumn{4}{|c|}{ Fixation Duration } & \multicolumn{2}{|c|}{ Preference Rating } \\
\hline $0 \%$ (black) & $0.24 \pm 0.09$ & 3.96 & $0.21 \pm 0.06$ & 3.48 & 55.32 & 58.33 \\
\hline $25 \%$ & $\mathbf{0 . 2 3} \pm 0.07$ & - & $0.21 \pm 0.06$ & 3.98 & 25.53 & 35.42 \\
\hline $50 \%$ & $0.24 \pm 0.07$ & 4.85 & $\mathbf{0 . 2 0} \pm 0.06$ & - & 19.15 & 6.25 \\
\hline $75 \%$ & $0.24 \pm 0.09$ & 4.41 & $0.21 \pm 0.07$ & 4.98 & - & - \\
\hline Text/Background Colors & \multicolumn{4}{|c|}{ Fixation Duration } & \multicolumn{2}{|c|}{ Preference Rating } \\
\hline black/creme & $\mathbf{0 . 2 1} \pm 0.07$ & - & $0.19 \pm 0.05$ & 3.89 & 15.22 & 24.62 \\
\hline blue/yellow & $0.21 \pm 0.08$ & 2.88 & $0.18 \pm 0.05$ & 1.11 & 10.87 & 10.78 \\
\hline green/brown & $0.22 \pm 0.07$ & 6.25 & $0.19 \pm 0.06$ & 7.78 & 6.52 & - \\
\hline off-black/off-white & $0.22 \pm 0.08$ & 6.73 & $0.20 \pm 0.06$ & 11.67 & 4.35 & 13.85 \\
\hline black/white & $0.22 \pm 0.07$ & 7.21 & $0.20 \pm 0.06$ & 8.33 & 10.87 & 23.08 \\
\hline light green/dark brown & $0.23 \pm 0.07$ & 9.62 & $0.20 \pm 0.04$ & 12.78 & 8.70 & 4.62 \\
\hline blue/white & $0.23 \pm 0.07$ & 9.62 & $\mathbf{0 . 1 8} \pm 0.05$ & - & 10.87 & 6.15 \\
\hline black/yellow & $0.23 \pm 0.09$ & 10.58 & $0.19 \pm 0.05$ & 5.00 & 32.61 & 16.92 \\
\hline Font Size & \multicolumn{4}{|c|}{ Fixation Duration } & \multicolumn{2}{|c|}{ Preference Rating } \\
\hline 14 points & $0.26 \pm 0.09$ & 24.52 & $0.22 \pm 0.07$ & 19.89 & - & - \\
\hline 18 points & $0.23 \pm 0.07$ & 12.02 & $0.20 \pm 0.05$ & 7.53 & 10.42 & 6.82 \\
\hline 22 points & $0.22 \pm 0.06$ & 3.85 & $0.20 \pm 0.05$ & 6.45 & 39.58 & 34.09 \\
\hline 26 points & $\mathbf{0 . 2 1} \pm 0.05$ & - & $\mathbf{0 . 1 9} \pm 0.04$ & - & 50.00 & 59.09 \\
\hline Character Spacing & \multicolumn{4}{|c|}{ Fixation Duration } & \multicolumn{2}{|c|}{ Preference Rating } \\
\hline$-7 \%$ & $0.23 \pm 0.09$ & 15.84 & $0.20 \pm 0.06$ & 10.61 & 10.87 & - \\
\hline $0 \%$ & $0.21 \pm 0.07$ & 2.97 & $0.19 \pm 0.05$ & 6.15 & 36.96 & 65.31 \\
\hline$+7 \%$ & $\mathbf{0 . 2 0} \pm 0.06$ & - & $0.19 \pm 0.05$ & 3.35 & 32.60 & 16.33 \\
\hline$+14 \%$ & $0.21 \pm 0.06$ & 3.96 & $\mathbf{0 . 1 8} \pm 0.05$ & - & 19.57 & 18.37 \\
\hline Line Spacing & \multicolumn{4}{|c|}{ Fixation Duration } & \multicolumn{2}{|c|}{ Preference Rating } \\
\hline 0.8 lines & $0.23 \pm 0.07$ & 3.10 & $0.21 \pm 0.05$ & 0.98 & 4.44 & 10.42 \\
\hline 1 line & $0.24 \pm 0.07$ & 4.42 & $0.21 \pm 0.05$ & 1.47 & 33.33 & 39.58 \\
\hline 1.2 lines & $0.24 \pm 0.07$ & 4.87 & $0.21 \pm 0.06$ & 0.49 & 40.00 & 39.58 \\
\hline 1.4 lines & $\mathbf{0 . 2 3} \pm 0.06$ & - & $\mathbf{0 . 2 0} \pm 0.06$ & - & 22.22 & 10.42 \\
\hline Paragraph Spacing & \multicolumn{4}{|c|}{ Fixation Duration } & \multicolumn{2}{|c|}{ Preference Rating } \\
\hline 0.5 lines & $0.23 \pm 0.06$ & 5.90 & $0.20 \pm 0.05$ & 1.02 & 17.56 & 10.53 \\
\hline 1 line & $0.23 \pm 0.06$ & 3.64 & $0.20 \pm 0.05$ & 1.02 & 32.82 & 26.32 \\
\hline 2 lines & $\mathbf{0 . 2 2} \pm 0.05$ & - & $\mathbf{0 . 2 0} \pm 0.04$ & - & 22.90 & 57.89 \\
\hline 3 lines & $0.22 \pm 0.05$ & 0.45 & $0.20 \pm 0.05$ & 0.51 & 26.72 & 5.26 \\
\hline Column Width & \multicolumn{4}{|c|}{ Fixation Duration } & \multicolumn{2}{|c|}{ Preference Rating } \\
\hline 22 char./line & $0.22 \pm 0.06$ & 2.34 & $0.19 \pm 0.04$ & 2.14 & 27.27 & 2.27 \\
\hline 44 char./line & $\mathbf{0 . 2 1} \pm 0.06$ & - & $0.19 \pm 0.05$ & 1.60 & 31.81 & 54.55 \\
\hline 66 char./line & $0.22 \pm 0.06$ & 3.27 & $\mathbf{0 . 1 9} \pm 0.04$ & - & 31.81 & 36.36 \\
\hline 88 char./line & $0.22 \pm 0.05$ & 0.47 & $\mathbf{0 . 1 9} \pm 0.04$ & - & 9.09 & 6.82 \\
\hline
\end{tabular}

Table 2 Fixation Duration and Preference Rating results for group D $(N=45)$ and group C $(N=44)$. The average fixation time results and the standard deviation are presented in seconds and the percentage shows their fixation extra time in comparison with the lowest value. Numbers in boldface indicate the best cases.

$0.136, p=0.938$ ) on fixation duration. Moreover, there were no interaction effects of background grey scale and groups $(F(3,376)=0.252, p=0.860)$. The results of the post-hoc tests show that:

- Participants with dyslexia had significantly longer fixation durations $(\bar{x}=0.235, s=0.08$ seconds $)$ than the participants without dyslexia $(\bar{x}=0.207$, $s=0.06$ seconds, $p<0.001$ ) (Table 2).
Within Groups: No significant effect of background grey scale was found on fixation duration in group $\mathrm{D}(F(3,188)=0.188, p=0.904)$, or in group $\mathrm{C}$ $(F(3,188)=0.204, p=0.893)$.

Preferences: Participants with and without dyslexia found pure black background significantly more readable than text presented with different grey scales $\left(\chi^{2}(3)=11.101, p=0.011\right.$ for group $\mathrm{D}$ and $\chi^{2}(3)=$ 
Fig. 4 Participants' reading performance (fixation duration mean) and preference ratings in $\%$ for text and background colors.
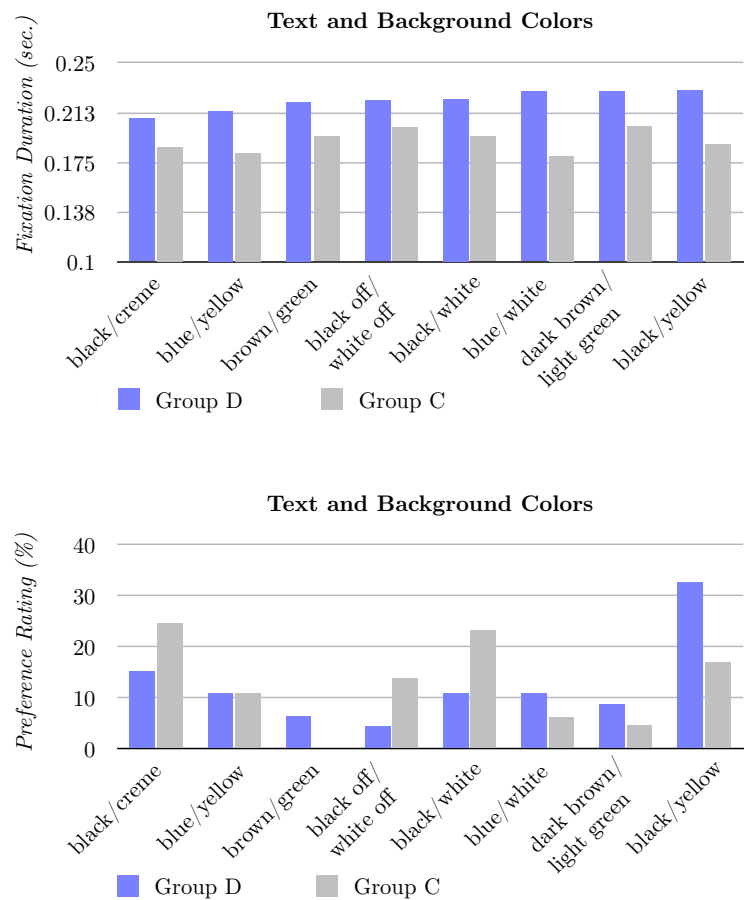

21.790, $p<0.001$ for group C). See Figure 3 for the fixation duration means and preferences.

\subsection{Text and Background Colors}

Main effects: With two-way ANOVA, significant main effects were found for the groups $(F(1,732)=$ 40.028, $p<0.001)$ on fixation duration. However, no effects of text and background colors $(F(7,732)=$ 0.848, $p=0.548)$ were found on fixation duration. Moreover, no interaction effects of text and background colors and groups $(F(7,732)=0.528, p=0.814)$ have been found either. The results of the post-hoc tests show that:

- Participants with dyslexia had significantly longer fixation durations $(\bar{x}=0.221, s=0.08$ seconds) than the participants without dyslexia $(\bar{x}=0.193$, $s=0.06$ seconds, $p<0.001$ ) (Table 2 ).

Within Groups: There was no significant effect of text and background colors on fixation duration for group $\mathrm{D}(F(7,366)=0.467, p=0.858)$ nor for group $\mathrm{C}$ $(F(7,366)=1.149, p=0.332)$.

Preferences: Participants with and without dyslexia did not find any of the text and background colors sig-
Fig. 5 Participants' reading performance (fixation duration mean) and preference ratings in $\%$ for font size.
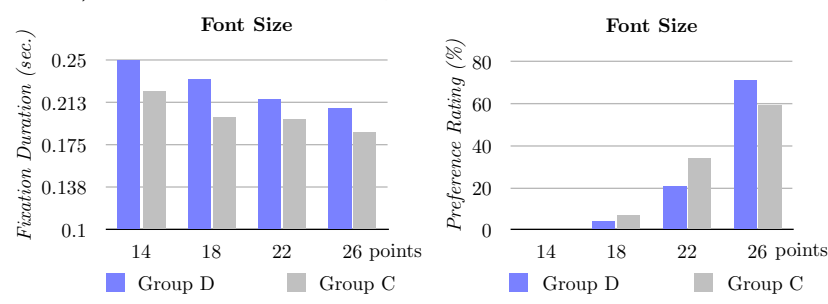

nificantly more readable $\left(\chi^{2}(7)=11.821, p=0.107\right.$ for group D and $\chi^{2}(7)=10.290, p=0.172$ for group $C$ ).

See Figure 4 for the fixation duration means and preferences.

\subsection{Font Size}

Main effects: With two-way ANOVA, significant main effects were identified in the fixation duration for the groups $(F(1,372)=19.713, p<0.001)$ and for font size $(F(3,372)=8.804, p<0.001)$. There was no interaction effect for font size and groups $(F(3,372)=$ $0.458, p=0.712)$. The results of the post-hoc tests show that:

- Group D had significantly longer fixation durations $(\bar{x}=0.229, s=0.07$ seconds $)$ than group $\mathrm{C}(\bar{x}=$ $0.202, s=0.05$ seconds, $p<0.001$ ) (Table 2 ).

- Participants present significant longer fixation durations with 14 points font size than with 18 points $(p=0.054), 22$ points $(p=0.002)$ and 26 points $(p<0.001)$ (Table 2).

Within Groups: A significant effect of font size on fixation duration in group $\mathrm{D}(F(3,186)=4.965, p=0.002)$ and in group $\mathrm{C}(F(3,186)=4.043, p=0.008)$ was found. The results of the post-hoc tests show that:

- For group D font size of 26 points lead to significant shorter fixation durations $(\bar{x}=0.208, s=0.05$ seconds) than texts with 14 points $(\bar{x}=0.259, s=0.09$ seconds, $p=0.003)$; and font size of 22 points lead to significant shorter fixation durations $(\bar{x}=0.216$, $s=0.06$ seconds) than texts with 14 points $(\bar{x}=$ $0.259, s=0.09$ seconds, $p=0.003$ ) (Table 2 ).

- Participants in group $C$ had significant shorter fixation durations with 26 points font size $(\bar{x}=0.186$, $s=0.04$ seconds $)$ than with 14 points $(\bar{x}=0.223, s$ $=0.07$ seconds, $p=0.005$ ) (Table 2 ).

Preferences: Participants with and without dyslexia found texts sizes of 26 points significantly easier to read 
Fig. 6 Participants' reading performance (fixation duration mean) and preference ratings in \% for character spacing.
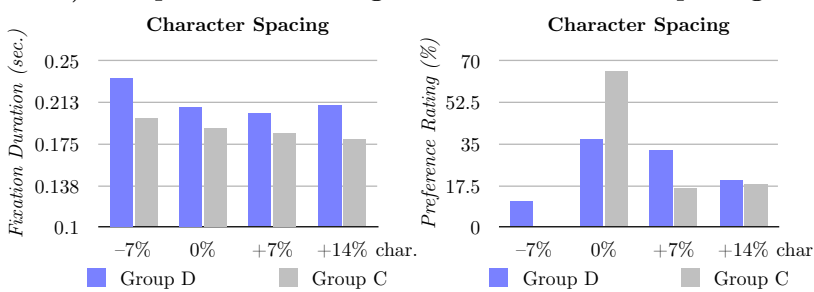

than the rest of the sizes $\left(\chi^{2}(3)=9.051, p=0.03\right.$ for group D and $\chi^{2}(3)=20.789, p<0.01$ for group $\left.\mathrm{C}\right)$.

See Figure 5 for the fixation duration means and preferences.

\subsection{Character Spacing}

Main effects: With two-way ANOVA, significant main effects were found for the groups $(F(1,368)=$ 16.35, $p<0.001)$ and for character spacing $(F(3,368)=2.86, p=0.037)$ of fixation duration. A significant interaction of character spacing and groups $(F(3,368)=0.52, p=0.665)$ has also been identified.

The results of the post-hoc tests show that:

- There is a significant difference of fixation duration between group $\mathrm{D}(\bar{x}=0.212, s=0.07$ seconds $)$ and group $\mathrm{C}(\bar{x}=0.188, s=0.05$ seconds, $p<0.001)$ (Table 2).

- Participants present significant longer fixation durations with character spacing $-7 \%$ than with spacing $+7 \%(p=0.035)$ and spacing $+14 \%(p=0.013)$, but not with $1 \%(p=0.140)$ (Table 2$)$.

Within Groups: No significant effect of character spacing on fixation duration for group $\mathrm{D}(F(3,184)=$ $1.896, p=0.132)$ or for group $\mathrm{C}(F(3,184)=$ $1.283, p=0.282)$ were identified.

Preferences: Participants with dyslexia did not find any of the options significantly easier to read $\left(\chi^{2}(3)=\right.$ 2.025, $p=0.567)$, while participants without dyslexia found text with $0 \%$ character spacing significantly more readable $\left(\chi^{2}(3)=21.542, p<0.001\right)$.

See Figure 6 for the fixation duration means and preference ratings.

\subsection{Line Spacing}

Main effects: With two-way ANOVA, significant main effects were identified for the groups $(F(1,372)=$ 17.793, $p<0.001)$ on fixation duration. No effects of
Fig. 7 Participants' reading performance (fixation duration mean) and preference ratings in $\%$ for line spacing.
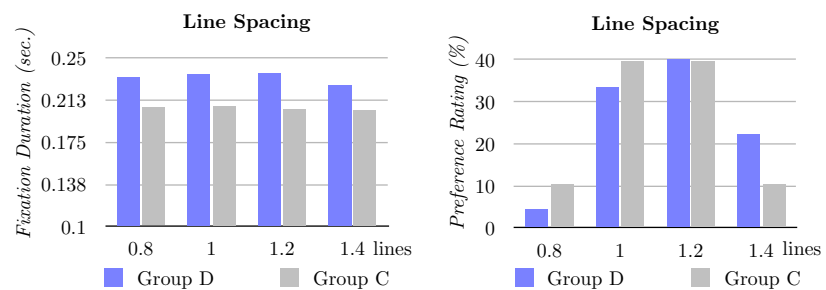

Fig. 8 Participants' reading performance (fixation duration mean) and preference ratings in \% for paragraph spacing.
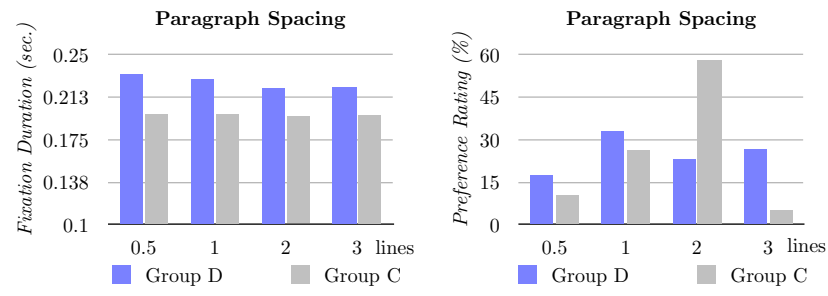

line spacing $(F(3,372)=0.238, p=0.870)$ on fixation duration were identified. However, there were no interaction effects of line spacing and groups $(F(3,372)=$ $0.109, p=0.955)$. The results of the post-hoc tests show that:

- Group D had significantly longer fixation durations $(\bar{x}=0.233, s=0.07$ seconds) than group $\mathrm{C}(\bar{x}=$ $0.206, s=0.06$ seconds, $p<0.001$ ) (Table 2 ).

Within Groups: No significant effect of line spacing on fixation duration for group $\mathrm{D}(F(3,186)=0.267, p=$ $0.849)$ or for group $\mathrm{C}(F(3,186)=0.032, p=0.993)$ has been identified.

Preferences: Participants did not find any of the options of line spacing significantly easier to read $\left(\chi^{2}(3)=\right.$ 2.164, $p=0.539$ for group $\mathrm{D}$ and $\chi^{2}(3)=3.179, p=$ 0.365 for group $\mathrm{C}$ ).

See Figure 7 for the fixation duration means and preference ratings.

\subsection{Paragraph Spacing}

Main effects: With two-way ANOVA, significant main effects were found for the groups $(F(1,374)=$ $28.545, p<0.001)$ on fixation duration. However, no effects were found of paragraph spacing $(F(3,374)=$ $0.453, p=0.715)$ on fixation duration. Also, interaction effects of paragraph spacing and groups $(F(3,374)=$ $0.234, p=0.873$ ) could not be found.

The results of the post-hoc tests show that: 
- Group C had significantly shorter fixation durations $(\bar{x}=0.197, s=0.05$ seconds $)$ than group $\mathrm{D}(\bar{x}=$ $0.225, s=0.06$ seconds, $p<0.001$ ) (Table 2 ).

Within Groups: No significant effect of paragraph spacing on fixation duration for group $\mathrm{D}(F(3,187)=$ $0.544, p=0.652)$ or for group $\mathrm{C}(F(3,187)=$ $0.024, p=0.995)$ has been identified.

Preferences: Participants did not find any of the options of line paragraph significantly easier to read $\left(\chi^{2}(3)=2.357, p=0.502\right.$ for group $\mathrm{D}$ and $\chi^{2}(3)=$ $2.813, p=0.421$ for group $\mathrm{C}$ ).

See Figure 8 for the fixation duration means and preferences.

\subsection{Column Width}

Main effects: With two-way ANOVA, significant main effects for the groups $(F(1,372)=30.776, p<0.001)$ on fixation duration were found. However, there was no effects of column width $(F(3,372)=0.155, p=0.927)$ on fixation duration. Moreover, there were no interaction effects of column width and groups $(F(3,372)=$ $0.216, p=0.886$ ).

The results of the post-hoc tests show that:

- Group C had significantly shorter fixation durations $(\bar{x}=0.189, s=0.05$ seconds $)$ than group $\mathrm{D}(\bar{x}=$ $0.217, s=0.05$ seconds, $p<0.001$ ) (Table 2 ).

Within Groups: There was no significant effect of column width on fixation duration for group D $(F(3,186)=0.176, \quad p=0.913)$ nor for group $\mathrm{C}$ $(F(3,186)=0.201, p=0.895)$.

Preferences: Participants with dyslexia did not find any of the options of column width significantly easier to read $\left(\chi^{2}(3)=0.845, p=0.839\right)$, while participants without dyslexia found the option of 44 characters per line significantly more readable $\left(\chi^{2}(3)=14.750, p=\right.$ $0.002)$.

See Figure 9 for the fixation duration means and preferences.

\section{Discussion}

General Comments. In general, participants without dyslexia read significantly faster and had shorter fixation durations than participants with dyslexia. For the font size variable, participants with dyslexia had significantly shorter fixation durations when using bigger fonts compared to smaller fonts.
Fig. 9 Participants' reading performance (fixation duration mean) and preference ratings in $\%$ for column width.
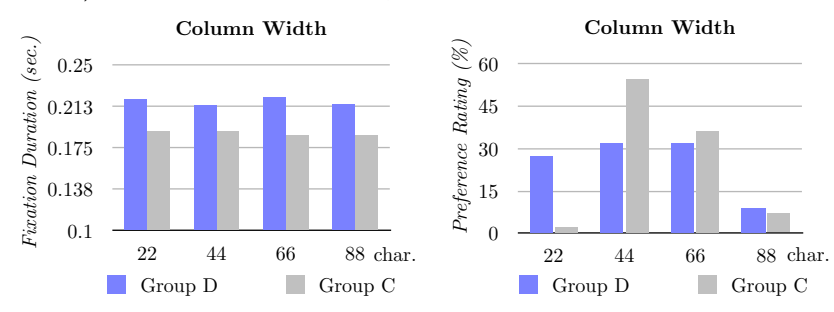

Although no more significant effects were found, people with dyslexia were in general more sensitive to text-presentation changes, since they presented larger differences in fixation duration among the different conditions.

Regarding the differences between the groups, the results are consistent with other eye tracking studies that found significant differences among the two populations $[41,46,72,75,76]$.

Regarding the sensitivity of fixation duration with respect to the parameters, there are clearly two different groups for people with dyslexia, even when normalizing with respect to the range of values used in each parameter. The first group is the set of parameters that affect reading performance in a large percentage $(10 \%$ or above), which are in order of importance: font size, character spacing, text and background color, and text grey scale. This group seems to suggest that the most important high-level characteristic that the text needs, is to let people to distinguish letters well. The second group, where impact is $5 \%$ or less, is formed by paragraph spacing, background gray scale, line spacing and column width. This suggests that distinguishing words and lines is less important, and that most probably, word spacing also does not have a large impact in readability (unless it gets really small).

For group $\mathrm{C}$ the order above changes a bit, though groups remain the same. In the first group, character spacing moves to the last position (fourth). In the second group paragraph spacing moves to the last position and column width and line spacing are swapped. However, as the readability impact of these three parameters mentioned is $2 \%$ or less, the order is not really relevant. Each parameter is discussed in detail in the following.

Text Grey scale. Using a pure black text on a pure white background is not recommended for people with dyslexia due to its high contrast, as many of them are sensitive to the brightness and this can cause the words to swirl or blur together [11]. No effects on objetive readability could be found. Most of participants without dyslexia $(93,88 \%)$ chose black over white as the 
most readable option, maybe because it is the most frequent color combination used in computer screens. However, only $60 \%$ of the participants with dyslexia chose this option.

Background Grey scale. No recommendations about grey scale background for people with dyslexia could be found, apart from the suggestion of using light grey as background [101], such as the color with the following hexadecimal code: FFFFE5 [89]. No differences on the objective readability of the participants could be identified. However, most of the study participants said that grey actually did not help them. Further experiments shall be carried out about the role of the background, because light on dark has different readability requirements than dark on light [21].

Text and Background Color. Poor color selections are one of the key problems encountered by people with dyslexia when reading [55]. Although the pair offblack/off-white is the one recommended for Web accessibility for dyslexics [11], it was the least often selected by the participants with dyslexia (only two selected it). The most preferred color pair chosen by the participants with dyslexia was black over yellow, which is not consistent with [11], who recommends to avoid high contrast (black/white is the highest contrast combination). According to [67], high contrasts creates so much vibration that it diminishes readability. Also, mucky green/brown and blue/yellow pairs were chosen by people with dyslexia, as in the experiments carried out by Gregor and Newell [36,37].

Surprisingly, the most often selected pair (black/yellow) has the highest mean for the fixation durations (0.23 seconds). As comparison, the average of the color combinations is 0.22 seconds. On the other hand, the color pair which was the fastest to read was black/creme (mean of 0.21 for the fixation duration). This pair of colors is used by the British Dyslexia Association for their website. ${ }^{11}$

According to the W3C algorithm [110], brightness differences of less than 125 and color differences of less than 500 are not supposed to be good. All the pair colors selected by the participants match this guideline, except dark brown/light mucky green pair (brightness difference: 107, color difference: 240). However, the readability of colored text/background pairs is influenced by the size of the text [21] and the size used in this study was 20 points.

For group C, higher preferences ratings were strongly correlated with shorter fixations. In this case

\footnotetext{
11 http://www.bdadyslexia.org.uk/
}

blue/white and blue/yellow where the best pairs of colors, suggesting than in future experiments blue/creme should also be tried.

Font Size. Another key problem experienced by people with dyslexia is finding the text too small [55]. Although the recommended font size for this target group is 12 or 14 points $[1,12,11]$, some readers with dyslexia may prefer a larger font $[25,12]$.

For both groups, texts presented with 18, 22, and 26 point size led to significant shorter fixation durations compared to texts with 14 points. For participants with dyslexia, texts with 22 and 26 points also led to significant shorter fixation durations than texts with 14 points. Hence, larger font sizes are more readable for people with and without dyslexia.

Unexpectedly, more than half of the participants with and without dyslexia, 24 and 26 respectively, selected the biggest option (26 points). None chose the smaller option, 14 points, which is already a recommended and relatively big font size. Since all the columns had the same width (a mean of 50 characters for 12 points), column width could not influence these decisions. Further investigations shall be carried out to find the font size preferred by people with and without dyslexia, as clearly there must be a turning point where a very large size starts making the reading more difficult.

In a later study, Rello et al [87] tested the effect of font size and line spacing on Wikipedia web pages using eye tracking. They found significant improvements (in objective readability and comprehensibility) within groups starting from 18 points font size instead of 22 points. This can be due to the fact that this study measured the impact of font size in the context of the Web and not in raw text.

Character Spacing. Pedley recommends creating a slightly larger distance between individual words and reduce letter-spacing slightly [66], so that the letters within a word lie closer together while Rainger suggests to have large spacing between letter combinations [71]. Zorzi et al. [113] conducted studies on paper not on screen- obtaining that larger character spacings improved the reading performance of children with dyslexia (reading speed and reading errors).

Consistently, the results of the present study show that participants (groups D and C) present significant shorter fixation durations with character spacing of $+7 \%$ and $+14 \%$, while $-7 \%$ lead to significant longer fixation durations. However, no differences within groups could be found. Also, the results show that most of the participants without dyslexia significantly prefer 
the standard spacing among characters (32 users) and that participants with dyslexia prefer either the standard separation or more separated characters (17 users for $0 \%$ and 15 for $+7 \%$ ).

Line Spacing. Even though it is recommended to use a line spacing of 1.5 to 2 [71], the results show that line spacing does not have a significant effect on the participants' readability and preferences. Similarly, in [87] line spacing was tested using eye tracking finding no effects on objective readability.

Paragraph Spacing. According to Bradford [11], paragraphs - even when they have a single line-- should always be spaced out with an empty line between each paragraph. However, the effect of paragraph spacing on objective readability and on the user preferences has been found in the results of the present study.

Column Width. Accordingly to $[11,12]$, which recommend to avoid long lines -60 to 70 characters - and to avoid narrow columns [12], most of the participants preferred the intermediate values: paragraphs with lines of 44 (14 users in group D and 24 in group C) or 66 characters (14 users in group D and 16 in group C). These results are not comparable with Schneps et al. [91] since they used a 34 points font and other devices in their experiment. Some of the participants said that they preferred the text with the widest column because they believed it was shorter than the others. Since the texts had the same number of words a side effect of having a wider column width was that the text had less lines and seemed to be shorter.

\section{Limitations of the Study}

Even if in shallow languages, as Spanish [93], one of the main characteristic of reading with dyslexia is that their reading process is slower [24], shorter fixation durations can be used as indicator of text readability, not as a possible alleviation of the issues related to dyslexia and reading.

One limitation of the study is that it only uses fixation duration as a measure of reading performance. Other measures such as reading errors were not used because the reading was done in silence trying to emulate natural online reading. Reading time was also not used because the texts lengths were not the same. Comprehension could also have been used as a measure, however it was only used as a control variable because the text presentation was modified for different fragments among the two stories and it was not possible to discriminate if the comprehension was due to comprehending a single fragment or the whole story. Further studies shall overcome this limitation and measure objective readability using more dependent measures.

Moreover, the texts tested were small so the results are not extensible to longer reading tasks such as emails or heavy-text web pages. For instance, the effect of font size and line spacing was tested on Wikipedia pages using eye tracking and a significant effect for only people with dyslexia started at 18 points font size instead of 22 points as in the present study [87].

Another limitation is that this study does not take into consideration the interaction effects between variables. All the conditions were tested independently. While Tinker found multiple interactions between various typographical parameters [97] others did not [8, 87]. One example of interactions found by Tinker [96] was between font size and line width, showing that long lines, very short lines, and small type size, and the combinations of these lead to significantly slower readings. Using eye tracking, Beymer et al. [8] compared font size and font type and found no significant effects. Also, no interaction effects between font size and line width were found in Rello et al. [87] when reading Wikipedia texts.

A recent study [112] has shown that brain processing differs from prose to poetry. The authors are not aware the are no studies that compare the interaction of dyslexia and prose versus poetry. The fact that both genres have been used in the experiment could have added a hidden variable. However, all levels of each of the conditions were always shown with the same kind of text. Only line spacing and paragraph spacing used texts in prose.

One of the reasons that could explain why the comprehension was so high in the study is that the different use of text customization could have enhanced the comprehension. For instance, Frase and Schwartz used line breaking to increase the speed of comprehension [32].

\section{Text Customization Recommendations}

Table 3 presents a set of recommendations for formatting screen text in a more accessible way for people with dyslexia. Both quantitative data for the readability (objective readability) of the text given by the eye tracker and the user preferences (subjective readability) have been considered. Since the user preferences might change with time [5] priority was given to the objective readability data in the recommendations. The authors' own results regarding font type are included, because the experimental setting was very similar: same default text presentation, same equipment (eye tracker), 


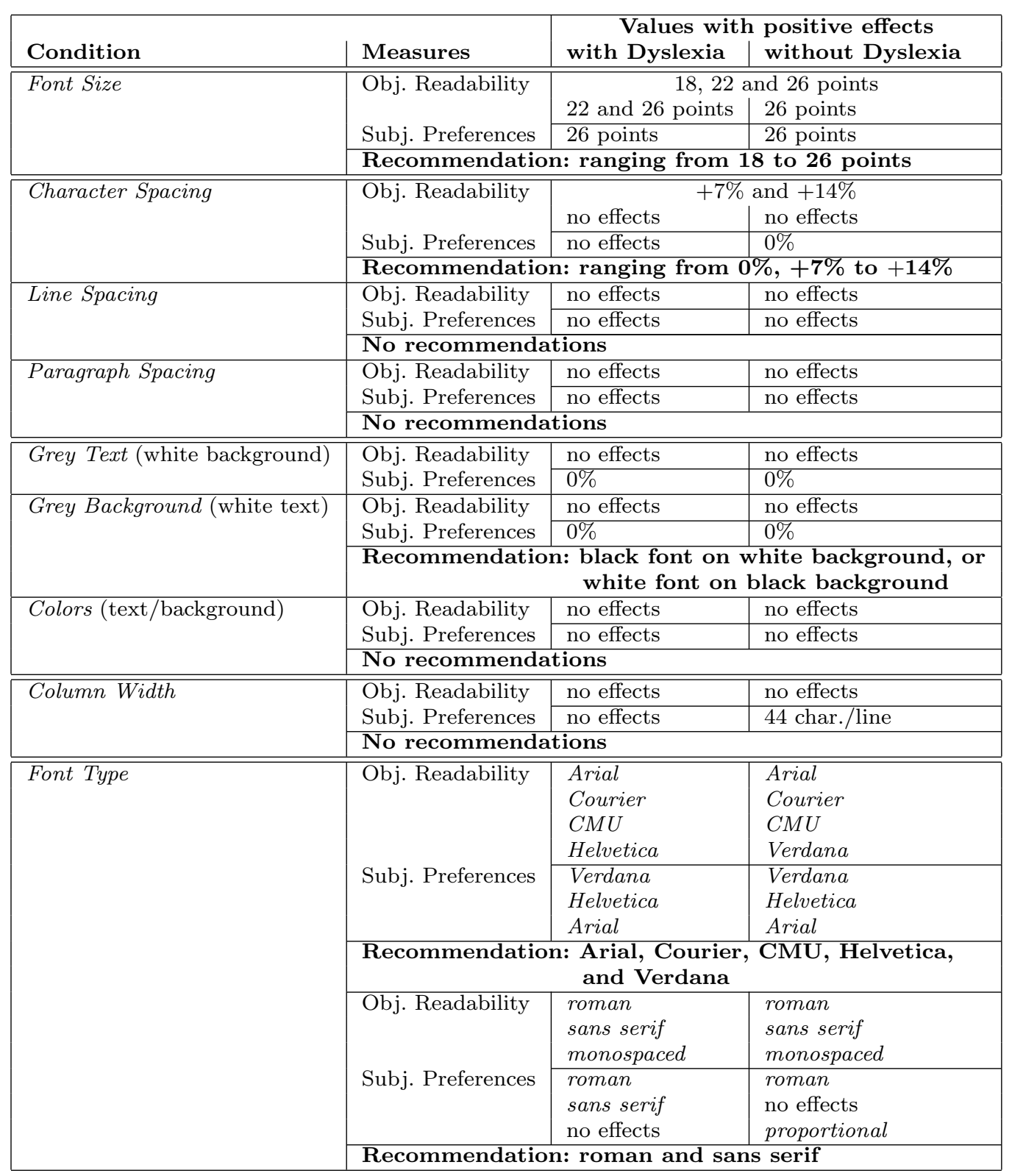

Table 3 Text customization results and recommendations for more readable screen text. Each of the parameters are independent from each other and no interactions between them were tested in the experiments. Font Size and Character Spacing distinguish between effects taking into account both groups and within groups because different effects were found in both cases.

same independent and dependent variables and similar methodology [79].

Notice that the results for each of the parameters are independent from each other and no interactions between them were tested in the experiment. These are only text customization recommendations, the combination of the parameters and the final customization of the text are left to the user. Certain studies have shown the benefits of self text customization $[37,25]$. Furthermore, WebAIM [106], British Dyslexia Association [12], as well as the Web Accessibility Initiative
(WAI) [110] recommend text customization. Furthermore, depending on the individual, dyslexia could potentially show reading performance issues in many possible ways. Also, the degree of severity differs from individual to individual [108]. This suggests that text customizability is more likely to better support the overall population than a single option. Therefore the recommendations addressed in this work shall be taken as a starting setting for text customization. Nonetheless, note that only half of the participants with dyslexia and without dyslexia- are able to guess correctly which 
text parameters lead them to an objective faster reading.

According to the results of this study, the parameters that enhance readability are very similar for both, people with and without dyslexia. Even if reading times for group $\mathrm{C}$ will be still smaller than for group D, these recommendations can be used for all the population without problems as the difficulty of reading is being balanced.

\section{Conclusions and Future Work}

The effect of eight text presentation parameters on objective readability and subjective preferences for people with and without dyslexia was tested. For readability, the main conclusions are that:

- Larger font sizes significantly improve readability, especially for people with dyslexia (ranging from 18 to 24 points);

- Larger character spacings (up to $+7 \%-+14 \%$ ) significantly improve readability for people with and without dyslexia;

- Regarding preferences, both groups found texts with no grey scales and with larger font sizes significantly more readable;

- Participants without dyslexia also found texts with standard character spacing and 44 characters per line column width significantly more readable.

These findings can have impact on screen text presentation recommendations and on the text options chosen by developers, designers, or content producers when they target people with dyslexia. For instance, these recommendations have been adapted and included in two eBook readers for people with dyslexia, one for Android (IDEAL eBook Reader [47]) and one for iOS (DysWebxia Reader [83]), in a game for children with dyslexia Piruletras or Dyseggxia [85], and in the Text4All $[99,100]$ web service. ${ }^{12}$ Below the recommendations are summarized and Figure 10 shows an example that uses the text recommendations for font size and character spacing, where the rest of the customization parameters were left to the user [80]:

- Font Size: 18, 22 and 26 points (17-Inch screen).

- Character Spacing: ranging from 0\%, $+7 \%$ to $+14 \%$.

- Font/Background Colors: black font on white background, or white font on black background.

- Typeface: Arial, Courier, CMU, Helvetica, or Verdana.

- Font Style: roman and sans serif.

\footnotetext{
12 http://www.text4all.net/.
}

Fig. 10 Text example using the dyslexic-accessible recommendations for font size and character spacing. There is no evidence that the effects would be cumulatively positive.

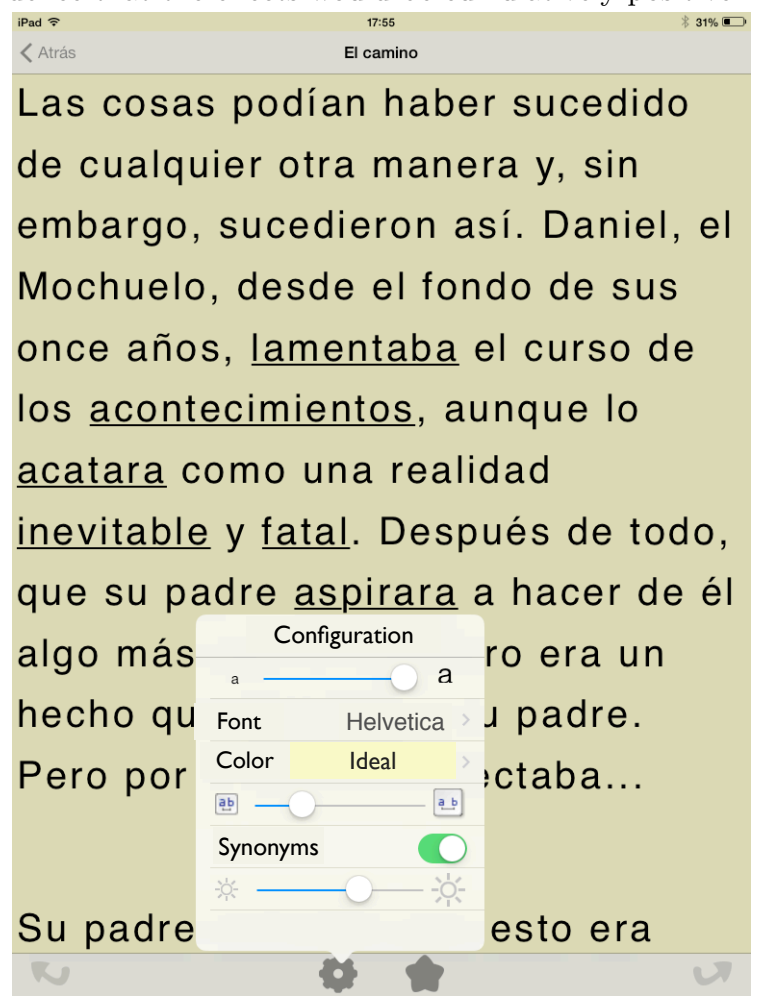

However, there are still problems found by individuals with dyslexia which remain unsolved. Given that dyslexia is a learning disability that affects language, it can be assumed that accessibility can be approached not only in terms of text presentation, but also in terms of text content [4]. The use of complicated language has been extensively pointed out as one of the key problems for this target group. For instance, more frequent and shorter words may improve readability for people with dyslexia $[24,82]$, so they may benefit from tools that modify the text content by performing lexical simplification $[80,81]$. The authors are currently exploring which other text-modification strategies apart from lexical simplification might be beneficial for users with dyslexia.

Acknowledgements The authors would like to thank MariCarmen Marcos for her assistance with the eye tracking hardware. Special thanks to the participants with dyslexia and their families.

\section{References}

1. Al-Wabil, A., Zaphiris, P., Wilson, S.: Web navigation for individuals with dyslexia: an exploratory study. Universal Access in Human Computer Interaction. Coping with Diversity 4554, 593-602 (2007) 
2. American Psychiatric Association: Diagnostic and statistical manual of mental disorders: DSM-IV-TR. American Psychiatric Publishing, Inc. (2000)

3. Baeza-Yates, R., Rello, L.: Estimating dyslexia in the Web. In: Proc. W4A 2011. ACM Press, Hyderabad, India (2011)

4. Baeza-Yates, R., Rello, L., Dembowski, J.: A contextaware synonym simplification algorithm: CASSA. In: Proc. NAACL '15. ACM, Denver, Colorado, USA (2015)

5. Barnum, C.M.: Usability Testing Essentials: Ready, Set... Test! Morgan Kaufmann (2010)

6. Beauvois, M.F., Derouesne, J.: Phonological alexia: three dissociations. Journal of Neurology, Neurosurgery \& Psychiatry 42, 1115-1124 (1979)

7. Berninger, V.W., Nielsen, K.H., Abbott, R.D., Wijsman, E., Raskind, W.: Writing problems in developmental dyslexia: Under-recognized and under-treated. Journal of School Psychology 46(1), 1-21 (2008)

8. Beymer, D., Russell, D., Orton, P.: An eye tracking study of how font size and type influence online reading. In: Proceedings of the 22nd British HCI Group Annual Conference on People and Computers: Culture, Creativity, Interaction - Volume 2, BCS-HCI '08, pp. 15-18. British Computer Society, Swinton, UK, UK (2008). URL http://dl.acm.org/citation.cfm? id $=1531826$. 1531831

9. Boldyreff, C., Burd, E., Donkin, J., Marshall, S.: The case for the use of plain English to increase Web accessibility. wse p. 42 (2001)

10. Bouma, H., Legein, C.P.: Foveal and parafoveal recognition of letters and words by dyslexics and by average readers. Neuropsychologia 15(1), 69-80 (1977)

11. Bradford, J.: Designing web pages for dyslexic readers (2011). http://www.dyslexia-parent.com/mag35.html

12. British Dyslexia Association: Dyslexia style guide (2012). http://www.bdadyslexia.org.uk/

13. Bruck, M.: The word recognition and spelling of dyslexic children. Reading Research Quarterly pp. 51-69 (1988)

14. Bruck, M.: Word-recognition skills of adults with childhood diagnoses of dyslexia. Developmental Psychology 26(3), 439 (1990)

15. Bruck, M.: Component spelling skills of college students with childhood diagnoses of dyslexia. Learning Disability Quarterly pp. 171-184 (1993)

16. Brunswick, N.: Unimpaired reading development and dyslexia across different languages. In: S. McDougall, P. de Mornay Davies (eds.) Reading and dyslexia in different orthographies, pp. 131-154. Psychology Press, Hove (2010)

17. Caldwell, B., Cooper, M., Reid, L.G., Vanderheiden, G.: Web content accessibility guidelines (WCAG) 2.0. WWW Consortium (W3C) (2008)

18. Carrillo, M.S., Alegría, J., Miranda, P., Pérez, S.: Evaluación de la dislexia en la escuela primaria: Prevalencia en español (Evaluation of dyslexia in primary school: The prevalence in Spanish). Escritos de Psicología (Psychology Writings) 4(2), 35-44 (2011)

19. Chapman, C.: The most popular fonts used by designers (2011). http://www. webdesignerdepot.com/2011/ 08/the-most-popular-fonts-used-by-designers/

20. Cohen, L., Dehaene, S., Verstichel, P.: Number words and number non-words: A case of deep dyslexia extending to Arabic numerals. Brain 117, 267-279 (1994)

21. Collier, D.: Colour text legibility (2012). http://www.hgrebdes.com/colour/spectrum/ colourvisibility.html
22. Coltheart, M., Masterson, J., Byng, S., Prior, M., Ridoch, J.: Surface dyslexia. The Quarterly Journal of Experimental Psychology A: Human Experimental Psychology 35A, 469-495 (1983)

23. Cornoldi, C., Oakhill, J.V.: Reading comprehension difficulties: Processes and intervention. Routledge (2013)

24. Cuetos, F., Valle, F.: Modelos de lectura y dislexias (Reading models and dyslexias). Infancia y Aprendizaje (Infancy and Learning) 44, 3-19 (1988)

25. Dickinson, A., Gregor, P., Newell, A.F.: Ongoing investigation of the ways in which some of the problems encountered by some dyslexics can be alleviated using computer techniques. In: Proc. ASSETS'02, pp. 97-103. Edinburgh, Scotland (2002)

26. Dixon, M.: Comparative study of disabled vs. nondisabled evaluators in user-testing: dyslexia and first year students learning computer programming. Universal Access in Human Computer Interaction. Coping with Diversity pp. 647-656 (2007)

27. Elbro, C., Nielsen, I., Petersen, D.K.: Dyslexia in adults: Evidence for deficits in non-word reading and in the phonological representation of lexical items. Annals of dyslexia 44(1), 203-226 (1994)

28. Ellis, A.W.: Reading, writing and dyslexia. Erlbaum, London (1984)

29. Evans, B.: Dyslexia and vision, vol. 5. Wiley (2001)

30. Evans, B.J., Cook, A., Richards, I.L., Drasdo, N.: Effect of pattern glare and colored overlays on a simulatedreading task in dyslexics and normal readers. Optometry \& Vision Science 71(10), 619-628 (1994)

31. Evett, L., Brown, D.: Text formats and web design for visually impaired and dyslexic readers-clear text for all. Interacting with Computers 17, 453-472 (2005)

32. Frase, L.T., Schwartz, B.J.: Typographical cues that facilitate comprehension. Journal of Educational Psychology $\mathbf{7 1}(2), 197$ (1979)

33. Frith, U.: A developmental framework for developmental dyslexia. Annals of dyslexia 36(1), 67-81 (1986)

34. García-Albea, J.E., Sánchez-Casas, R.M., Viso, S.: Efectos de la frecuencia de uso en el reconocimiento de palabras (Effects of usage frequency in word recognition). Investigaciones psicológicas (Psychological Research) 1, 24-63 (1982)

35. Goulandris, N.E.: Dyslexia in different languages: Crosslinguistic comparisons. Whurr Publishers (2003)

36. Gregor, P., Dickinson, A., Macaffer, A., Andreasen, P.: Seeword: a personal word processing environment for dyslexic computer users. British Journal of Educational Technology 34(3), 341-355 (2003)

37. Gregor, P., Newell, A.F.: An empirical investigation of ways in which some of the problems encountered by some dyslexics may be alleviated using computer techniques. In: Proc. ASSETS'00, ASSETS 2000, pp. 85-91. ACM Press, New York, NY, USA (2000)

38. Hagtvet, B.E.: Listening comprehension and reading comprehension in poor decoders: Evidence for the importance of syntactic and semantic skills as well as phonological skills. Reading and writing 16(6), 505-539 (2003)

39. Holmes, V., Carruthers, J.: The relation between reading and spelling in skilled adult readers. Journal of memory and language 39(2), 264-289 (1998)

40. Hyönä, J., Olson, R.K.: Eye fixation patterns among dyslexic and normal readers: Effects of word length and word frequency. Journal of Experimental Psychology: Learning, Memory, and Cognition 21(6), 1430 (1995) 
41. Inhoff, A.W., Rayner, K.: Parafoveal word processing during eye fixations in reading: Effects of word frequency. Perception \& Psychophysics 40(6), 431-439 (1986)

42. Interagency Commission on Learning Disabilities: Learning Disabilities: A Report to the U.S. Congress. Government Printing Office, Washington DC, U.S. (1987)

43. International Dyslexia Association: Definition of dyslexia: http://interdys.org/DyslexiaDefinition. htm (2011). Based in the initial definition of the Research Committee of the Orton Dyslexia Society, former name of the IDA, done in 1994

44. Jeanes, R., Busby, A., Martin, J., Lewis, E., Stevenson, N., Pointon, D., Wilkins, A.: Prolonged use of coloured overlays for classroom reading. British Journal of Psychology 88(4), 541-548 (1997)

45. Jiménez, J.E., Guzmán, R., Rodríguez, C., Artiles, C.: Prevalencia de las dificultades específicas de aprendizaje: La dislexia en español (the prevalence of specific learning difficulties: Dyslexia in Spanish). Anales de Psicología (Annals of Psychology) 25(1), 78-85 (2009)

46. Just, M.A., Carpenter, P.A.: A theory of reading: From eye fixations to comprehension. Psychological review 87, 329-354 (1980)

47. Kanvinde, G., Rello, L., Baeza-Yates, R.: IDEAL: a dyslexic-friendly e-book reader (poster). In: Proc. ASSETS'12, pp. 205-206. Boulder, USA (2012)

48. Keenan, J.M., Betjemann, R.S., Olson, R.K.: Reading comprehension tests vary in the skills they assess: Differential dependence on decoding and oral comprehension. Scientific Studies of Reading 12(3), 281-300 (2008)

49. Kriss, I., Evans, B.J.W.: The relationship between dyslexia and Meares-Irlen Syndrome. Journal of Research in Reading 28(3), 350-364 (2005)

50. Kurniawan, S., Conroy, G.: Comparing comprehension speed and accuracy of online information in students with and without dyslexia. Advances in Universal Web Design and Evaluation: Research, Trends and Opportunities, Idea Group Publishing, Hershey, PA pp. 257-70 (2006)

51. Landerl, K., Bevan, A., Butterworth, B., et al.: Developmental dyscalculia and basic numerical capacities: A study of 8-9-year-old students. Cognition 93(2), 99-125 (2004)

52. Lewis, C.: Using the "thinking-aloud" method in cognitive interface design. IBM TJ Watson Research Center (1982)

53. Lockley, S.: Dyslexia and higher education: accessibility issues. The Higher Education Academy (2002)

54. Lyon, G.R.: Toward a definition of dyslexia. Annals of Dyslexia 45(1), 3-27 (1995)

55. McCarthy, J.E., Swierenga, S.J.: What we know about dyslexia and web accessibility: a research review. Universal Access in the Information Society 9, 147-152 (2010)

56. McClelland, J.L.: Preliminary letter identification in the perception of words and non-words. Journal of Experimental Psychology: Human Perception and Performance 2(1), 80-91 (1976)

57. Mosberg, L., Johns, D.: Reading and listening comprehension in college students with developmental dyslexia. Learning Disabilities Research \& Practice (1994)

58. Nielsen, J.: Lower-literacy users (2012). Jakob Nielsen's Alertbox. http://www.useit.com/alertbox/20050314. html
59. O'Brien, B.A., Mansfield, J.S., Legge, G.E.: The effect of print size on reading speed in dyslexia. Journal of Research in Reading 28(3), 332-349 (2005)

60. Olson, R.K., Kliegl, R., Davidson, B.J.: Dyslexic and normal readers' eye movements. Journal of Experimental Psychology: Human Perception and Performance 9(5), 816 (1983)

61. Paciello, M.G.: Web accessibility for people with disabilities. CMP Books, Lawrence, Kansas (2000)

62. Patterson, K., Marshall, J.C., Coltheart, M.: Surface dyslexia: Neuropsychological and cognitive studies of phonological reading. Lawrence Erlbaum Associates, London (1985)

63. Patterson, K.E.: Neuropsychological approaches to the study of reading. British Journal of Psychology 72(2), 151-174 (1981)

64. Patterson, K.E.: The relation between reading and phonological coding: Further neuropsychological observations. Neurocase 1(3), 251-257 (1995)

65. Paulesu, E., Démonet, J.F., Fazio, F., McCrory, E., Chanoine, V., Brunswick, N., Cappa, S.F., Cossu, G., Habib, M., Frith, C.D., Frith, U.: Dyslexia: Cultural diversity and biological unity. Science 291(5511), 21652167 (2001)

66. Pedley, M.: Designing for dyslexics: Part 3 (2006). http://accessites.org/site/2006/11/ designing-for-dyslexics-part-3-of-3

67. Perron, C.: Colour choices on web pages: Contrast vs readability (2012). http://www.writer2001.com/ index.htm

68. Pirozzolo, F.J., Rayner, K.: The neural control of eye movements in acquired and developmental reading disorders. Studies in Neurolinguistics 4, 1-27 (1978)

69. Pollak, D.: Dyslexia, the self and higher education: Learning life histories of students identified as dyslexic. Trentham Books Ltd (2005)

70. Rack, J.P., Snowling, M.J., Olson, R.K.: The nonword reading deficit in developmental dyslexia: A review. Reading Research Quarterly pp. 29-53 (1992)

71. Rainger, P.: A dyslexic perspective on e-content accessibility (2012). www.texthelp.com/media/39360/ USDyslexiaAndWebAccess. PDF

72. Raney, G.E., Rayner, K.: Word frequency effects and eye movements during two readings of a text. Canadian Journal of Experimental Psychology 49(2), 151 (1995)

73. Rayner, K.: Eye movements and the perceptual span in beginning and skilled readers. Journal of experimental child psychology 41(2), 211-236 (1986)

74. Rayner, K.: Eye movements in reading and information processing: 20 years of research. Psychological Bulletin 124, 372-422 (1998)

75. Rayner, K., Duffy, S.A.: Lexical complexity and fixation times in reading: Effects of word frequency, verb complexity, and lexical ambiguity. Memory \& Cognition 14(3), 191-201 (1986)

76. Rayner, K., Raney, G.E.: Eye movement control in reading and visual search: Effects of word frequency. Psychonomic Bulletin \& Review 3(2), 245-248 (1996)

77. Rello, L., Baeza-Yates, R.: Lexical quality as a proxy for web text understandability (poster). In: Proc. WWW '12, pp. 591-592. Lyon, France (2012)

78. Rello, L., Baeza-Yates, R.: The presence of English and Spanish dyslexia in the Web. New Review of Hypermedia and Multimedia 8, 131-158 (2012)

79. Rello, L., Baeza-Yates, R.: Good fonts for dyslexia. In: Proc. ASSETS'13. ACM Press, Bellevue, Washington, USA (2013) 
80. Rello, L., Baeza-Yates, R.: Evaluation of Dyswebxia: A reading app designed for people with dyslexia. In: Proc. W4A '14. Seoul, Korea (2014)

81. Rello, L., Baeza-Yates, R., Bott, S., Saggion, H.: Simplify or help? Text simplification strategies for people with dyslexia. In: Proc. W4A '13. Rio de Janeiro, Brazil (2013)

82. Rello, L., Baeza-Yates, R., Dempere, L., Saggion, H.: Frequent words improve readability and short words improve understandability for people with dyslexia. In: Proc. INTERACT '13. Cape Town, South Africa (2013)

83. Rello, L., Baeza-Yates, R., Saggion, H., Bayarri, C., Barbosa, S.D.J.: An iOS reader for people with dyslexia (demo). In: Proc. ASSETS'13. ACM Press, Bellevue, Washington, USA (2013)

84. Rello, L., Bautista, S., Baeza-Yates, R., Gervás, P., Hervás, R., Saggion, H.: One half or 50\%? An eyetracking study of number representation readability. In: Proc. INTERACT '13. Cape Town, South Africa (2013)

85. Rello, L., Bayarri, C., Otal, Y., Pielot, P.: A computerbased method to improve the spelling of children with dyslexia using errors. In: Proc. The 16th International ACM SIGACCESS Conference of Computers and Accessibility (ASSETS 2014). Rochester, USA (2014)

86. Rello, L., Kanvinde, G., Baeza-Yates, R.: Layout guidelines for web text and a web service to improve accessibility for dyslexics. In: Proc. W4A '12. ACM Press, Lyon, France (2012)

87. Rello, L., Pielot, M., Marcos, M.C., Carlini, R.: Size matters (spacing not): 18 points for a dyslexic-friendly Wikipedia. In: Proc. W4A '13. Rio de Janeiro, Brazil (2013)

88. Rubenstein, H., Garfield, L., Millikan, J.A.: Homographic entries in the internal lexicon1. Journal of Verbal Learning and Verbal Behavior 9(5), 487-494 (1970)

89. de Santana, V.F., de Oliveira, R., Almeida, L.D.A., Baranauskas, M.C.C.: Web accessibility and people with dyslexia: a survey on techniques and guidelines. In: Proc. W4A '12, p. 35. ACM (2012)

90. Santana, V.F., Oliveira, R., Almeida, L.D.A., Ito, M.: Firefixia: An accessibility web browser customization toolbar for people with dyslexia. In: Proc. W4A '13. Rio de Janeiro, Brazil (2013)

91. Schneps, M.H., Thomson, J.M., Sonnert, G., Pomplun, M., Chen, C., Heffner-Wong, A.: Shorter lines facilitate reading in those who struggle. PloS ONE 8(8), e71,161 (2013)

92. Schuberth, R.E., Eimas, P.D.: Effects of context on the classification of words and non-words. Journal of Experimental Psychology: Human Perception and Performance 3(1), 27-36 (1977)

93. Seymour, P.H.K., Aro, M., Erskine, J.M.: Foundation literacy acquisition in European orthographies. British Journal of psychology 94(2), 143-174 (2003)

94. Speech Therapy Association of Catalonia: PRODISCAT: Protocol de detecció i actuació en la dislèxia. Àmbit Educativo (Protocol for detection and management of dyslexia. Educational scope.). Education Department of the Catalonian government (2011)

95. Temple, C.M.: Developmental analogues to acquired phonological dyslexia. In: Dyslexia: a global issue. Martinus Nijhoff Publishers, La Haya (1984)

96. Tinker, M.A.: Influence of simultaneous variation in size of type, width of line, and leading for newspaper type. Journal of Applied Psychology 47(6), 380 (1963)

97. Tinker, M.A.: Legibility of print, vol. 1. Iowa State University Press Ames (1963)
98. Tobii Technology: Product description of Tobii 50 Series (2005)

99. Topac, V.: The development of a text customization tool for existing web sites. In: Text Customization for Readability Symposium (2012)

100. Topac, V.: Improving text accessibility and understanding of domain-specific information. Ph.D. thesis, Universitatea Politehnica Timişoara (2014)

101. Tseng, A.: Six surprising bad practices that hurt dyslexic users (2012). http://uxmovement.com/content/ 6-surprising-bad-practices-that-hurt-dyslexic-users/

102. United Nations Committee of the General Assembly: Convention on the Rights of Persons with Disabilities. United Nations, New York (2006)

103. Valle, F.: Reading errors in Spanish. In: Reading and writing problems in different systems. Kluwer (1988)

104. Vellutino, F.R., Fletcher, J.M., Snowling, M.J., Scanlon, D.M.: Specific reading disability (dyslexia): What have we learned in the past four decades? Journal of child psychology and psychiatry 45(1), 2-40 (2004)

105. Warrington, E., Zangwill, O.L.: A study of dyslexia. Journal of Neurology, Neurosurgery, and Psychiatry 20(3), 208 (1957)

106. WebAIM: Web accessibility in mind (2014). http:// webaim.org/

107. Wimmer, H.: Characteristics of developmental dyslexia in a regular writing system. Applied psycholinguistics 14(1) (1993)

108. Wolf, M., O'Rourke, A.G., Gidney, C., Lovett, M., Cirino, P., Morris, R.: The second deficit: An investigation of the independence of phonological and namingspeed deficits in developmental dyslexia. Reading and Writing 15(1-2), 43-72 (2002)

109. World Health Organization: International statistical classification of diseases, injuries and causes of death (ICD-10), tenth edn. World Health Organization (1993)

110. World Wide Web Consortium (W3C): Web accessibility initiative (WAI) (2011). http://www.w3.org/WAI/

111. Zarach, V.: Ten guidelines for improving accessibility for people with dyslexia (2012). CETIS University of Wales, Bangor. http://wiki.cetis.ac.uk/ Ten_Guidelines_for_Improving_Accessibility_for_ People_with_Dyslexia

112. Zeman, A., Milton, F., Smith, A., Rylance, R.: By heart an fmri study of brain activation by poetry and prose. Journal of Consciousness Studies 20(9-10), 9-10 (2013)

113. Zorzi, M., Barbiero, C., Facoettia, A., Lonciari, I., Carrozzi, M., Montico, M., Bravar, L., George, F., PechGeorgel, C., Ziegler, J.: Extra-large letter spacing improves reading in dyslexia. Proceedings of the National Academy of Sciences 109, 11,455-11,459 (2012) 


\section{Appendix A: Color and Brightness}

The CYMK/RGB codes for the contrast and colors used are:

\section{Text contrast:}

- 0\% (pure black font, 000000/0,0,0): Brightness text: 255; Brightness background: 0; Brightness difference: -255 ; Color difference: 765 .

- 25\% (404040/64,64,64): Brightness text: 255; Brightness background: 63; Brightness difference: 192; Colour difference: 573 .

- 50\% (7E7E7E/126,126,126): Brightness text: 255; Brightness background: 126; Brightness difference: 129; Colour difference: 387 .

- 75\% (BFBFBF/191,191,191): Brightness text: 255; Brightness background: 191; Brightness difference: 64; Colour difference: 191 .

Background contrast:

- 100\% (pure black background, 000000/0,0,0): Brightness text: 0; Brightness background: 255; Brightness difference: -255; Color difference: 765 .

- 25\% (404040/64,64,64): Brightness text: 63 ; Brightness background: 255; Brightness difference: -192 ; Colour difference: 573 .

- 50\% (7E7E7E/126,126,126): Brightness text: 126; Brightness background: 255; Brightness difference: -129 ; Colour difference: 387.

- 75\% (BFBFBF/191,191,191): Brightness text: 191; Brightness background: 255; Brightness difference: -64; Colour difference: 191.

Colors:

- black (000000/0,0,0) / white (FFFFFF/255,255,255): Color difference: 765 , Brightness difference: 255 ;

- off-black $(0 \mathrm{~A} 0 \mathrm{~A} 0 \mathrm{~A} / 10,10,10) /$ off-white(FFFFE5 $/ 255,255,259$ ): Color difference: 735 , Brightness difference: 245;

- black $(000000 / 10,10,10)$ / yellow (FFFF00/255,255,0): Color difference: 510, Brightness difference: 226;

- blue $(00007 \mathrm{D} / 0,0,125)$ / white (FFFFFF/255,255,255): Color difference: 640, Brightness difference: 241;

- dark brown $(1 \mathrm{E} 1 \mathrm{E} 00 / 30,30,0)$ / light mucky green (B9B900/185,185,0): Color difference: 310, Brightness difference: 137

- brown $(282800 / 40,40,0)$ / mucky green (A0A000/160,160,0): Color difference: 240, Brightness difference: 107

- black $(000000 / 0,0,0)$ / creme (FAFAC8/250,250,200): Color difference: 700 , Brightness difference: 244;

- blue $(00007 \mathrm{D} / 0,0,125)$ / yellow $(\mathrm{FFFF} 00 / 255,255,0)$ : Color difference: 635, Brightness difference: 212

\section{Appendix B: Text Example}

¿Soy dix-leso?

by Marcela Paz (Papelucho series)

Por la tarde fuimos al doctor. Era un señor bastante preguntón, que se hacía el simpático por fuera, pero se notaba que era malo por dentro. Me martilló las costras y otras cuestiones con un martillito lindo. Y mientras hablaba y hablaba con la mamá se martillaba su otra mano gorda.

Yo pensaba qué pasaría si en vez de su mano gorda se martillara el tremendo grano que tenía en la nariz? Pero apenas se lo rascó y siguió dale que dale hablando de "este niño". Y "este niño" por aquí y "este niño" por allá.

Traté de entender lo que decían.

Casi lo entendí. No estoy seguro si la cosa es que soy superdotado o viceversa. Menos mal que además parece que soy dixleso, que es algo muy guay y como distinto. Y tampoco me importa mucho ser así.

Mis padres fueron al colegio a hablar con mi profe $\mathrm{y}$ volvieron furiosos.

De todos modos yo tengo mi enfermedad propia y nadie me la quita.

Pero en la noche, me desvelé. Porque claro, en el día a uno le gusta ser enfermo y en la noche no. Así que desperté a mi padre apretetándole la nariz porque es el único modo de despertarlo. 